\title{
EL ESTATUS DE LA ARQUEOlogía HISTÓRICA. A PROPÓSITO DEL ESTUDIO DEL CONSUMO DE TEJA FRANCESA EN SAN JUAN BAUTISTA, TABASCO, MÉXICO
}

\section{THE STATUS OF HISTORICAL ARCHEOLOGY. REGARDING OF THE STUDY OF THE CONSUMPTION OF FRENCH TILE IN SAN JUAN BAUTISTA, TABASCO, MEXICO}

\author{
Miguel GUEVARA CHUMACERO ${ }^{1 *}$ y Vladimira PALMA LINARES ${ }^{2 * *}$
}

\author{
${ }^{1}$ Universidad de Ciencias y Artes de Chiapas, Antiguo camino a San Gabriel S/N, Chiapa de Corzo, Chiapas \\ ${ }^{2}$ Universidad Autónoma del Estado de México, Centro Universitario Tenancingo. Carretera Tenancingo - \\ Villa Guerrero Km. 1.5 Tenancingo, Estado de México \\ * Correo electrónico: miguel.guevara@unicach.mx \\ ** Correo electrónico: vladimirapl@hotmail.com
}

\begin{abstract}
Resumen: Los arqueólogos usan la arqueología histórica de diferentes maneras. Algunos de los términos utilizados, como subdisciplina, se definen de manera amplia e imprecisa. Por esta razón el objetivo de este trabajo es discutir los conceptos del campo de la arqueología histórica, junto con una presentación del método para obtener los datos necesarios para la explicación del registro arqueológico. De manera particular se centra en el análisis de tejas francesas obtenidas de las extensas investigaciones arqueológicas realizadas en el asentamiento de San Juan Bautista, Tabasco, México que data de finales del siglo XIX. Se utiliza la información histórica y los datos de arqueología experimental como fuentes de analogía. Este estudio concluye señalando la razón de la baja densidad de tejas en la muestra, dado que se consideraron objetos de alto valor de reemplazo al ser obtenidos de las redes de comercio internacional. En particular, este trabajo desarrolla una perspectiva alternativa al estudio de la arqueología histórica, a través de un método que resuelve los problemas de reduccionismo teórico y la creación de tautología, causados por el inductivismo.
\end{abstract}

Palabras Clave: arqueología histórica, epistemología, analogía, arqueología experimental, tejas.

\begin{abstract}
Archaeologists use historical archeology in different ways. Some of the terms used, such as subdiscipline, are defined in a broad and imprecise way. For this reason, the objective of this work is to discuss the concepts of the field of historical archeology, together with a presentation of the method to obtain the necessary data for the explanation of the archaeological record. Focusing mainly upon specimens of french roof tiles obtained from the extensive archaeological investigations were conducted at the ancient settlement of San Juan Bautista, Tabasco, México. Historical information and experimental archeology data are used as analog sources. This study concludes by pointing out the reason for the low density of tiles in the sample given that they were considered objects of high replacement value as they were obtained from international trade networks. In particular, this work develops an alternative perspective to the study of historical archeology, through a method that solves the problems caused by inductivism, such as theoretical reductionism and the creation of tautologies.
\end{abstract}

Keywords: historical archaeology, epistemology, analogy, experimental archaeology, roof tiles.

Sumario: 1. Introducción. Las definiciones de la arqueología histórica. 2. Entre estrategias y arqueologías temáticas. 3. El estatus de la arqueología histórica. 4. Un caso a manera de ejemplo. El consumo de teja francesa en San Juan Bautista, Tabasco. 4.1. Una hipótesis desde el registro histórico. 4.2. Analogía desde la arqueología experimental. 4.3. Implicaciones contrastadoras de las hipótesis. 5. Conclusiones. La ciencia de la deducción. 6. Bibliografía. 


\section{Introducción. Las definiciones de la arqueo- logía histórica}

A partir de mediados de la década de los años sesenta, la arqueología vio surgir una proliferación de formas de investigación: arqueología experimental, arqueología de género, etnoarqueología, arqueología industrial, arqueología de la identidad, arqueología de la basura. Entre estas formas de investigación se situaba la arqueología histórica.

Esta diversificación respondía en gran medida a la aparición de nuevos programas de investigación que resaltaban la necesidad de evaluar las explicaciones que hacíamos sobre el registro arqueológico (Binford 1988). Sin embargo con el paso de los años se ha perdido la noción del lugar que ocupan estas formas de investigación dentro de nuestra disciplina. Un caso muy concreto es lo que se ha escrito sobre la arqueología histórica.

A manera de ejemplo, se menciona que la arqueología histórica es un sub-campo de la arqueología (Fournier, 1985: 27; Schuyler, 1978), o se trata como una subdisciplina (DeCorse, 2014: 114; Fournier y Charlton, 2012: 460) e incluso es considerada como una disciplina separada (Dante y Chirinos, 2020: 3; Lees y King, 2007). Si a ello sumamos otros términos que se designan como arqueología colonial, arqueología de sitios históricos o arqueohistoria (Schuyler, 1978), entonces la clasificación resulta sumamente difusa.

Estos enfoques nos llevan a preguntarnos: ¿La arqueología histórica es una nueva rama de la arqueología, es un campo de investigación, una subdivisión disciplinaria, metodologías, o sólo es un calificativo? La problemática envuelta es que estos términos se lleguen a emplear únicamente como rúbricas bajo el slogan "que proliferen las etiquetas".

Queremos proceder de otra manera. Por esa razón el objetivo de este ensayo es explorar el problema de la definición del lugar que ocupa la arqueología histórica dentro de la disciplina. Es un esfuerzo de reflexión teórica, más cercano al campo de la posición metafísica. De forma particular se pretende la clarificación de las nociones fundamentales de la naturaleza de la arqueología histórica en términos epistemológicos. Posteriormente se abordará una propuesta metodológica del empleo de información histórica en arqueología, enfocado en la noción del método. Hay escasos estudios de esta índole en la literatura de la arqueología histórica y en su mayoría se escribió en la década de los setenta (South, 1977) con revisiones importantes aunque esporádicas en la reciente década (DeCorse, 2014; Montón y Abejez, 2015) de ahí la relevancia de esta discusión.

En su mayor parte, la disciplina arqueológica está asociada a una tradición empirista (Bate y Terrazas, 2006), razón por la cual, para ejemplificar la aplicación del método que se propone, se recurre a los patrones de consumo y desecho de teja francesa en un contexto histórico de finales del siglo XIX, recuperados en el centro de Villahermosa, Tabasco, en el sureste de México.

Pero demos comienzo por las definiciones. En la actualidad coexisten cinco grandes concepciones de la arqueología histórica. Se trata de las definiciones: a) restringida —en ocasiones también denominada particular-, b) general, c) global, d) amplia y, e) como método.

La concepción restringida es seguida por investigadores que establecen un límite desde un punto de vista cronológico (Blouet, 2014; Hall y Silliman, 2006; Mehler, 2013; Orser, 2012). El uso cronológicamente restringido, de ahí el término (Montón y Abejez, 2015: 12), se enfoca a los procesos de interacción que ocurrieron con la expansión europea a finales de la Baja Edad Media. En la arqueología histórica mexicana y algunos sectores de latinoamérica, la delimitación cronológica es restringida a los períodos que siguen al contacto cultural inicial entre europeos y las poblaciones indígenas locales, aplicándose a los períodos colonial (1521-1820 d.C.) y la post-independencia o período republicano -1821 al presente- (Fournier y Charlon, 2012).

Por otro lado, hay un conjunto de investigadores (DeCorse. 2014: 139; Fournier. 1985: 27) para quienes la arqueología histórica se define por hacer uso tanto del registro arqueológico como del histórico para entender a la sociedad bajo estudio. Esta sería la definición general de la arqueología histórica. Así se usa el término en un sentido general para referirse a cualquier investigación arqueológica que emplee materiales arqueológicos en combinación con fuentes de información histórica (textuales, orales, visuales, arquitectónicas, etc.).

James Deetz (1977: 5) desarrolló una concepción global del término, al definirlo como la arqueología relacionada al momento de la difusión de la cultura europea en todo el mundo y su impacto en los pueblos indígenas. Si bien se señala 
un corte temporal, a partir del siglo XV, el concepto global se basa en considerar al proceso de colonización como un factor de cambio caracterizado por una economía colonialista que varios autores asocian con la conformación del mundo moderno. Hay cuatro conceptos clave que definen sus postulados (Orser, 1996): el colonialismo global, eurocentrismo, capitalismo y modernidad. Es un punto de vista que ha tenido una gran repercusión en la manera que se trabaja contemporáneamente el concepto (Saucedo y Chirinos, 2020).

Existe una cuarta concepción del concepto que ha sido nombrada como la definición amplia de la arqueología histórica (Montón y Abejez, 2015: 12). Engloba el estudio de cualquier cultura o todos aquellos períodos en que se cuente con un registro escrito (Andrén, 1998; Funari, 2008; Funari et al., 1999). Se plantea así una lectura cronológicamente amplia de la arqueología histórica, ya que al incorporar el estudio de sociedades con escritura se tiene la posibilidad de estudiar periodos remotos y no está determinado a un momento histórico, como ocurre en la visión restringida, o por la implantación de un sistema económico, como lo determina la visión global (Montón y Abejez, 2015: 12).

En resumen, podemos señalar que tanto la arqueología general como la versión amplia, poseen una distinción metodológica, debido a que ambas basan su criterio de demarcación en la combinación del empleo de fuentes de información histórica y el registro arqueológico. Por su parte, la arqueología restringida o particular posee una delimitación temporal (Figura 1).

\section{Entre estrategias y arqueologías temáticas}

En términos de definición ¿la arqueología histórica podría considerarse un sub-campo o una subdisciplina de la arqueología? Definitivamente no. Sería un reduccionismo metodológico absurdo tal como señalar que la arqueología del periodo Formativo es una sub-disciplina al poseer una delimitación temporal, o decir que la arqueología de excavación es un sub-campo del trabajo arqueológico, al consistir de una metodología que comparte principios derivados de otras disciplinas como la geología.

En años recientes se ha buscado una solución a la condición de los diversos campos de estudio con que trabaja la arqueología, entre ellos la información histórica, a partir de la propuesta de Gándara (2007: 63). Así, se ha considerado que la arqueología histórica no sería sino una forma de arqueología temática. Éstas forman parte de una línea de investigación al tratar reflexiones organizadas en torno a un tema que puede enfocarse a un subconjunto de la totalidad social, por ejemplo, un corte temporal o técnico como en este caso. Las investigaciones por tema caracterizan a las llamadas arqueologías temáticas, entre las cuales estaría incluido el caso de la arqueología histórica según esta concepción.

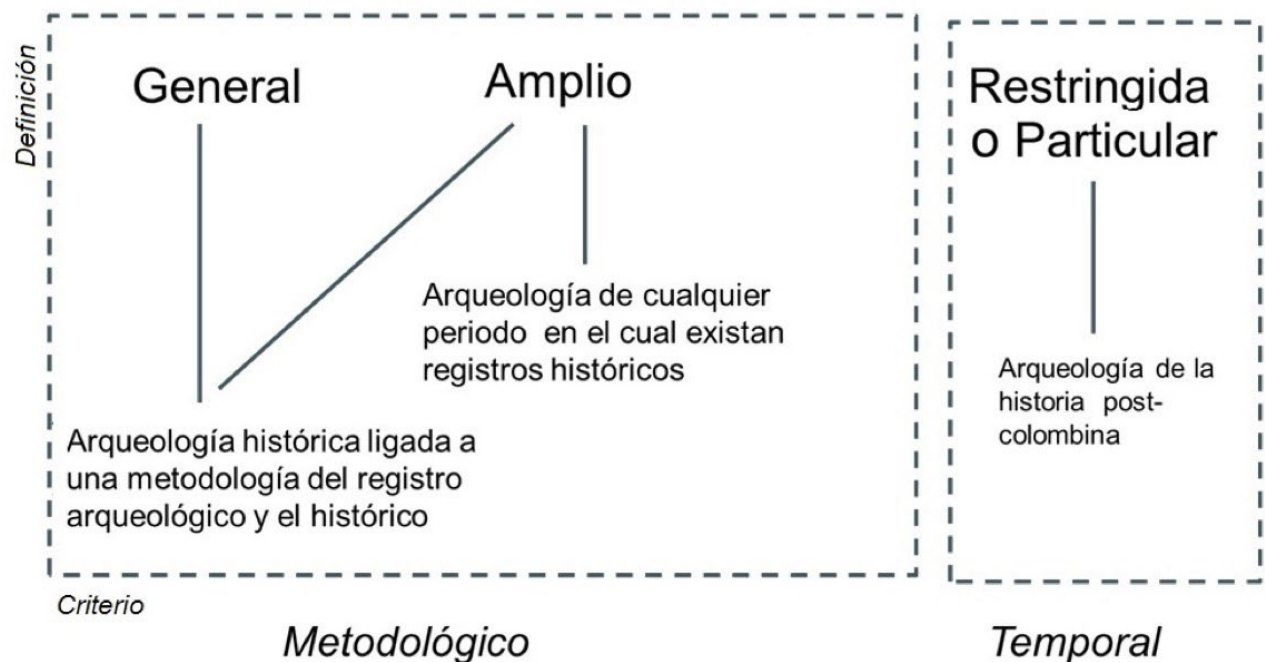

Figura 1. Criterios de distinción entre los conceptos de arqueología histórica. (Fuente: Elaboración propia). 
Así la arqueología histórica como arqueología temática, se puede referenciar como aquella en que el "filtro temático" es un periodo histórico determinado. 0 una variación en cuanto a la metodología con el empleo de fuentes documentales. En estos términos, no se trataría de una disciplina distinta a la arqueología, o subdisciplina de ésta; únicamente poseería una distinción en cuanto al periodo histórico o el uso de metodologías históricas.

En discusiones recientes, Gándara ha postulado (2007: 53) que existen variantes del trabajo arqueológico que no deben considerarse como arqueologías temáticas debido a que su estudio no privilegia un aspecto de la realidad social. En esta situación se encontraría aquellas cuyo enfoque es técnico y - como la arqueometría, la arqueología experimental, la etnoarqueología-, y a las cuales denomina arqueologías instrumentales. Las distingue de otro tipo de aproximación cuyo recorte es temporal. La ubicación de la arqueología histórica en estos rubros depende del enfoque que se le otorgue. Por ejemplo al definir la arqueología histórica bajo una concepción general formaría parte de una arqueología instrumentalista, dado que la distinción es metodológica por el uso de técnicas de documentación histórica. Pero si se concibe en términos cronológicos, bajo lo que hemos señalado como la definición restringida del término, sería una arqueología de corte temporal.

Una situación más complicada ocurre con la definición global. En este caso la arqueología histórica no se enfoca a realizar estudios de segmentos, sino de la totalidad social (Gándara, 2007: 53), como los procesos de colonialismo global, el imperialismo o el desarrollo del modo de producción capitalista. En este sentido remite a la incorporación o planteamientos desde otras disciplinas para desarrollar teorías sustantivas o heurísticas positivas.

No obstante, la arqueología histórica definida como arqueología temática o como arqueología instrumentalista/temporal, no nos permite identificar el lugar que ocupa dentro del cuerpo teórico de la arqueología. En otras palabras, no nos permite identificar su estatus.

En los años setenta, de manera muy propositiva, Jefferson Reid, Michael Schiffer y William Rathje en su texto Behavioral archaeology: Four strategies (1975), ya apuntaban que estas formas de hacer arqueología, incluida la arqueología histórica, no eran sino distintas estrategias de las cuales puede hacer uso la arqueología para explicar la conducta humana. Este ensayo fue pensado originalmente en 1972 cuando tanto Reid como Schiffer eran asistentes de clase de Rathje. De esos seminarios derivó un trabajo de cinco páginas que resumía una inquietud latente en esa época: la diversificación de la arqueología (Reid, 1995: 15). El texto fue presentado en la Society for American Archaeology hasta que finalmente fue publicado en 1975 en la revista American Antrhopologist. Posteriormente fue reimpreso en la introducción del imprescindible libro de M. Schiffer, Behavioral Archaeology.

Pero reseñaré el contenido del artículo para relatar su importancia. En primer lugar, definen arqueología de forma simple, como el estudio de las relaciones entre conducta humana y cultura material (Reid et al., 1975: 864). En este sentido, la arqueología no tendría límites temporales, de tal forma que nuestra disciplina puede estudiar tanto un campamento de caza recolección de hace 15000 años, como definir los patrones de consumo y desecho de una compañía refresquera en una ciudad actual.

Ahora bien, el arqueólogo se moverá en cuatro distintas estrategias según dos variables. La primera definida por la relación que desee estudiar, en este caso, la relación entre conducta humana y cultura material. Y la segunda variable que precisa si se pretende estudiar el pasado o el presente.

De esta forma, la estrategia 1 se refiere al uso de cultura material que fue hecha en el pasado para responder preguntas sobre la conducta del pasado. Corresponde a la arqueología tradicionalmente practicada. La estrategia 2 estudia la cultura material del presente con la finalidad de entender la conducta humana del pasado. La arqueología experimental y la etnoarqueología serían variantes de esta estrategia. La estrategia 3 estudia los restos materiales del pasado para derivar leyes culturales sobre la conducta del presente. Por último, la estrategia 4 estudia los objetos materiales del presente para describir y explicar la conducta humana del presente. Esta estrategia incluiría el estudio de las sociedades industriales y no industriales del presente, según los autores.

A pesar que los contextos históricos nos resultan cercanos en su dimensión temporal, corresponden ya a un tiempo pasado. La arqueología histórica se movería entonces dentro de la estrategia 1 como se deriva de las definiciones expuestas que expresan que se enfoca a estudiar el pasado 
en términos de conducta y cultura material dado que estos procesos temporalmente se remontan al producto del proceso de colonización europea.

Esta sería la estrategia en la que se ubicaría la arqueología histórica. No obstante, veinte años después, Jefferson Reid publica Four strategies after twenty years: A return of basics como parte del libro Expanding Archaeology (1995), donde examina y puntualiza algunos aspectos de la arqueología conductual y del texto original de las cuatro estrategias, como en los tres mosqueteros, a dos décadas de distancia. El modelo de las cuatro estrategias, nos dice Reid (1995), está definido por la relación entre conducta humana y objetos materiales, en el pasado y en el presente. De manera particular puntualiza que el modelo reconoce diferentes tipos de preguntas acerca de la relación entre conducta y cultura material. Las preguntas servirían para guiar el movimiento de la investigación entre las distintas estrategias. Este aspecto es muy importante ya que aclara algunos puntos del texto original de 1975. Las investigaciones pueden moverse de estrategia en estrategia según dicten las preguntas realizadas, que corresponden a los problemas de investigación que se pretendan resolver (Reid, 1995: 17). Así no solo se considera la relación conducta-cultura material en el pasado-presente, sino también las preguntas de investigación, que en nuestros términos correspondería a los objetivos de investigación.

Esta observación de Reid es importante, porque nos encamina al problema central que estamos tratando: los criterios de demarcación. Y la reflexión señalada se acerca al postulado defendido por Popper:

\section{"La creencia de que existen entidades como la física, la biología o la arqueolo- gía, y de que estos "estudios" o "discipli- nas" se distinguen por el tema que inves- tigan me parece un residuo de la época en que se creía que una teoría debía partir de una definición de su propio objeto de estudio." (Popper 1983: 95).}

Para este filósofo debería ocurrir una integración de estas disciplinas dado que no se estudian temas, sino problemas, los cuales atraviesan los límites de los objetos de estudio. "Somos estudiosos - nos dice Popper-de problemas, no de disciplinas".

Partiendo de este postulado popperiano, la arqueología histórica se estaría moviendo en dos estrategias distintas a partir de las preguntas que intenta resolver. En primer lugar tradicionalmente se ha enfocado a resolver problemas de la conducta humana del pasado por medio de cultura material también del pasado, por lo tanto se movería dentro de la estrategia 1 , como ya lo habíamos apuntado. Pero también se puede pretender que los principios obtenidos de la información histórica funcionen como una guía para conozcamos los procesos de formación que sufre el contexto arqueológico y que dan lugar a los patrones de cultura material que son registrados por el arqueólogo en el presente. En este sentido estudiamos la conducta del pasado para explicar los objetos materiales del presente, con lo cual estaríamos dentro de la estrategia 2 (Figura 2).

No obstante, a pesar de la revisión del modelo por parte de Reid, sigue sin respuesta una pregunta fundamental: ¿A qué se refieren los autores con el término estrategia? Quedan claras las variables que se consideran, además de la postulación que las investigaciones en cada una de las cuatro estrategias dependen de los objetivos de investigación. Pero aún así continúa siendo vaga la referencia del término estrategia. Por ejemplo, no queda del todo claro dentro de cuál componente de la teoría estaría ubicada una estrategia.

Quizás la respuesta esté en las propias palabras de Reid (1995: 17) quien nos dice: "No se trata de programas de investigación nuevos, sino de un modelo sencillo de relaciones entre evidencia e inferencia, ahora más comúnmente llamada teoría de rango medio". Efectivamente, estas estrategias en arqueología no se tratan de ramas o una sub-disciplina y mucho menos de nuevas teorías en el sentido holístico (o como Reid les llama programas de investigación, siguiendo seguramente el término de Lakatos). La clave es que quizás forman parte de lo que Binford (1988) denominó teorías de rango medio. Son teorías que hacen referencia a un campo de teorías intermedias entre las teorías sustantivas y los datos empíricos. Más específicamente, sugiero que las estrategias formarían parte del área metodológica de una teoría. En ese sentido se entiende que en este ámbito coincide la aplicación de varias técnicas, incluso derivadas de distintas disciplinas (metodología etnográfica, análisis químicos, encuestas cuantitativas, por mencionar algunas). Las estrategias a las que se hace referencia en los textos reseñados, tendrían un valor básicamente metodológico. Entonces, ¿la 


\begin{tabular}{|l|l|l|l|}
\multicolumn{2}{c|}{} & \multicolumn{2}{|l|}{ Objetos materiales } \\
\cline { 3 - 4 } \multicolumn{2}{c|}{} & Pasado & Presente \\
\hline Conducta humana & Pasado & ${ }^{1}$ Arqueologia histórica & ${ }^{2}$ Arqueologia histórica \\
\cline { 2 - 4 } & Presente & 3 & 4 \\
\hline
\end{tabular}

Figura 2. Estrategias de la arqueología y lugar que ocupa la arqueología histórica. (Fuente: Modificado de Reid, Schiffer y W. Rathje 1975).

arqueología histórica sería un componente de la metodología?

\section{El estatus de la arqueología histórica}

Comenzaré este apartado señalando la respuesta al problema. La arqueología histórica es un componente de la teoría arqueológica. Lo cual da lugar a nuevas preguntas. ¿Epistemológicamente cuál es su función, y ontológicamente dónde se ubica? Aquí los argumentos.

La arqueología realiza inferencias de procesos sociales no observables a partir de asociaciones comúnmente artefactuales, que sí puede observar. En ocasiones este procedimiento involucra la incorporación de datos no arqueológicos como lo puede ser el empleo de fuentes históricas. La validez de la transferencia y uso del registro histórico en arqueología está dada por la categoría de analogía. La analogía es un proceso de proyección de lo conocido a lo desconocido. En lógica la analogía es una forma de inferencia en la que una unidad que se corresponde en dos o más aspectos con otra unidad, puede también corresponderse en otros aspectos (Gándara, 1990). En esta situación el caso fuente de analogía, referida al uso de registro histórico, tenderá a ser más amplia y totalizadora que el registro arqueológico - debido a su carácter de incompletud, dado que tradicionalmente no observamos la conducta social de forma directaAsí, en el registro histórico utilizado como fuente de analogía, observaremos más aspectos que pueden proyectarse a la arqueología como sujeto de analogía.

Uno de los peligros de la proyección directa de la fuente al sujeto de analogía es el reduccionismo teórico. Se puede llegar a reducir la arqueología a la disciplina bajo la cual se realiza la comparación analógica, en este caso la historia. Lo anterior puede, en primer lugar, conducirnos a asumir de manera implícita los supuestos y problemas teóricos que pueden yacer de fondo en la disciplina que sirve de analogía. Por otro lado, nos conduce a negar la capacidad que tiene la arqueología para reconstruir los procesos sociales, ignorando el registro arqueológico que es lo que hace singular a nuestra disciplina (Guevara, 1997: 8). Por otra parte, el uso directo de la analogía conduce inevitablemente a un callejón sin salida llamado tautología. Partiendo de la proyección directa de aspectos de la fuente de analogía para explicar el registro arqueológico como sujeto de analogía, el conocimiento no solo resulta verdadero ante cualquier situación, ya que no hay un punto en el cual estos valores sean sujetos a evaluación. Sino también se regresa al planteamiento proyectado originalmente sin que haya ocurrido un acrecentamiento en el conocimiento.

Manuel Gándara (1990: 224), en un planteamiento sobre la legitimidad de la analogía etnográfica y por extensión de las distintas formas de analogía que empleamos los arqueólogos incluida la histórica, introduce el Principio Cortina. Este principio señala que la analogía es constitutiva de la teoría arqueológica. La teoría arqueológica, es definida como una teoría observacional en un sentido amplio. Menciono teoría observacional en el sentido amplio, dado que se reconoce una distinción entre la teoría de lo observable, que está relacionada con el componente ontológico y en nuestra disciplina se vincula con los procesos de formación del registro arqueológico; y también se reconoce una teoría de la observación propiamente dicha, que se relaciona con el aspecto epistemológico, es decir la forma que valoramos y realiza- 
mos su registro (Bate, 1998; Gándara, 2007). Bate (1998: 107) refiere a la teoría observacional en el sentido amplio, ligada a los procesos de formación y transformación de los contextos arqueológicos, la evaluación de las metodologías empleadas, así como la producción de la información. Una teoría observacional tiene por fin resolver problemas de la evaluación de las teorías y la selección de datos a observarse, como puede ser la manera de tomar en consideración los resultados de las mediciones, la forma de interpretar las observaciones y la justificación de las inferencias, así como el uso de técnicas (López, 1990: 42). Es por esta razón que dentro de las teorías de la observación encontramos las metodologías, las técnicas y de particular interés para este estudio, las heurísticas.

Una heurística se define como el planteamiento racional y sistemático de problemas de investigación y la planificación de procedimientos para la investigación (Bate, 1998: 8). Este conjunto de procedimientos nos da la posibilidad de ampliar la producción de inferencias, descubrir errores de planteamientos, generar nuevo conocimiento y enriquecer la teoría. Dentro de la teoría arqueológica, la analogía cumple la función de una heurística (Guevara, 1997: 8). Y plantear una analogía en relación a un problema puede conducir a la formulación de una hipótesis. En este sentido la analogía es una fuente para producir hipótesis.

La arqueología en su etapa de empleo de fuentes de información provenientes del registro histórico, debe considerarse como una forma de argumentación por analogía, y por lo tanto como una heurística cuya función es la formulación de hipótesis, por lo cual son constitutivos de una teoría observacional en arqueología. Es por esta razón que no se trata de una sub-disciplina o campo de investigación distinto a nuestra disciplina. Forma parte de la cotidiana construcción de la teoría arqueológica. Ese sería su estatus.

Ahora bien, la formulación de hipótesis mediante la analogía, a mi parecer debe seguir el método expuesto por Stiles (1977: 94-97) en estos términos:

Formulación de la analogía. Stiles plantea que hay dos tipos generales de analogía. La discontinua, también llamada comparativa general, en la cual no hay conexión en el espacio y en el tiempo entre la cultura que produce el contexto arqueológico y aquella que provee la analogía. El segundo tipo de analogía se conoce acercamiento histórico directo y ocurre cuando existe conexión en el tiempo y en el espacio entre la cultura del contexto arqueológico analizado y la fuente de analogía (Stiles, 1977: 95). Por su parte Gándara (1990) plantea que la selección de las propiedades consideradas relevantes para la formulación de analogías, proviene de los principios teóricos derivados de la teoría sustantiva.

Formulación de la hipótesis. Como respuesta al uso de analogías, los planteamientos obtenidos del registro histórico deben expresarse a través de la formulación de una hipótesis. Sería la etapa que Hempel (1973) reconocía como contexto de descubrimiento. El término formulación hace referencia al planteamiento de principios que se expresan mediante símbolos (que pueden o no ser matemáticos), o como es habitual en nuestra área de estudio, a través de enunciados declarativos.

Contrastación de la hipótesis. Concierne a la etapa que nos permitirá evaluar la legitimidad de los planteamientos hipotéticos derivados de la fuente de analogía. Corresponde al llamado contexto de justificación y es una fase fundamental para la construcción de nuestro campo teórico propio, ya que sometemos a contratación los argumentos derivados por analogía, mediante el propio registro arqueológico.

\section{Un caso a manera de ejemplo. El consumo de teja francesa en San Juan Bautista, Tabasco}

El caso para ejemplificar la forma en que sugerimos se debe emplear la información del registro histórico, proviene de un contexto del siglo XIX de San Juan Bautista, capital de Tabasco (actualmente con el nombre de Villahermosa), en el Golfo de México (Figura 3).

En el año de 2014, durante la sustitución de la red de drenaje y carpeta asfáltica en pleno centro histórico de la ciudad, se llevaron a cabo investigaciones arqueológicas en la sección oeste de la avenida F. Madero, que revelaron diversos depósitos y contextos que databan del siglo XIX y los primeros años del XX (Guevara y Pichardo, 2016). El estudio de la teja recuperada resultó significativo debido a que se trató de un bien utilitario obtenido por comercio a larga distancia, como se desprende de la información histórica y de sus características formales.

Para determinar el contexto de deposición final de estos artefactos, nos basamos en el análisis de distribución espacial que consistió en el registro tridimensional de cada artefacto de teja recupera- 


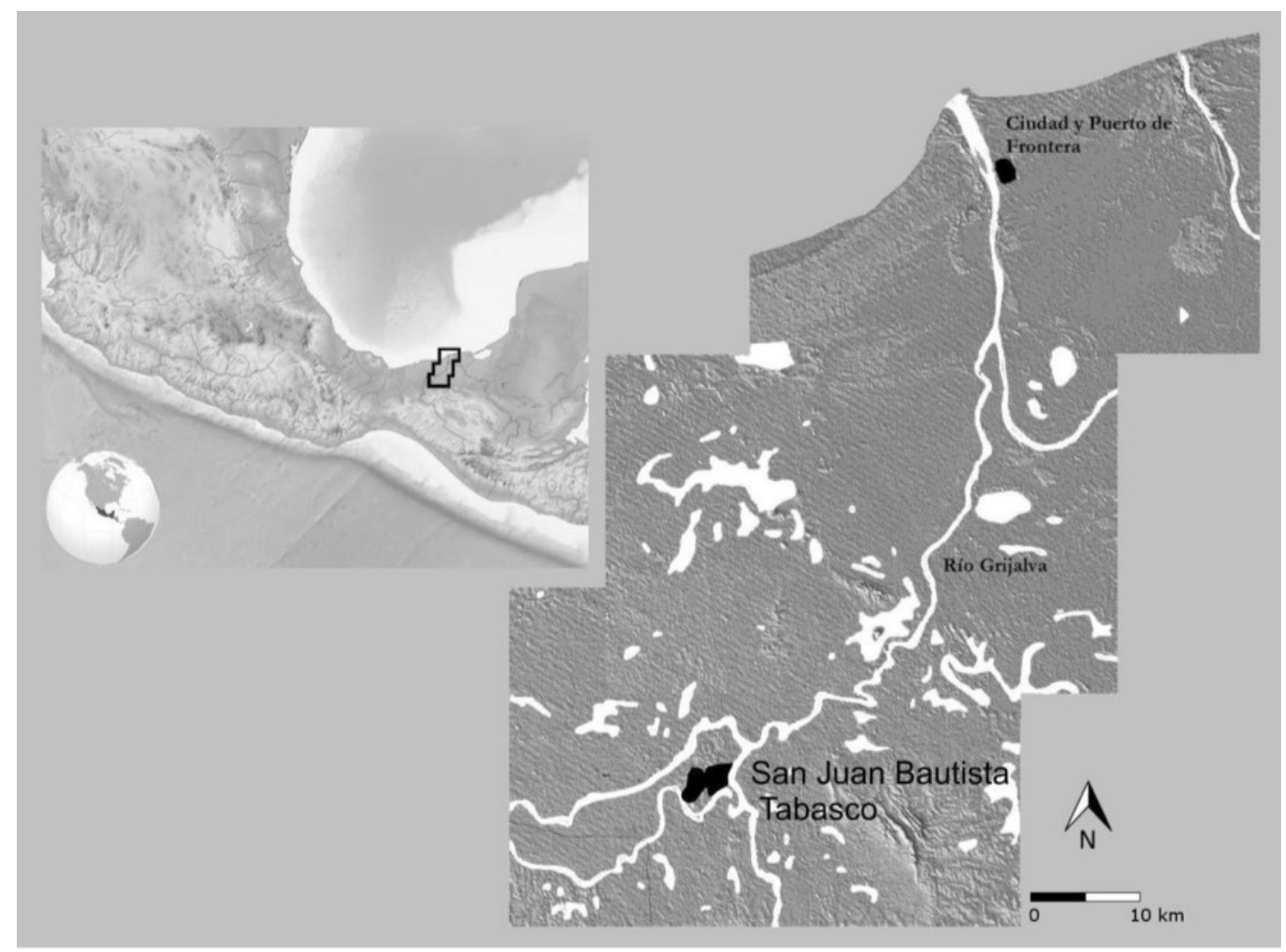

Figura 3. Ubicación de San Juan Bautista, Tabasco, México. (Fuente: Elaboración propia).

do. Y que se combinó con al análisis tipológico realizado a partir de la conformación de la base de datos de tal análisis, con lo cual se llevó a cabo la contextualización. Lo anterior permitió la identificación del tipo de teja por cada sector de excavación.

Las tejas recuperadas provienen de dos contextos. Del primero se registraron como desechos en basureros improvisados durante la etapa de construcción del drenaje maestro de la vialidad y la deposición de rellenos para cubrirlo, relleno que además funcionó para desplantar la calle Primera Grijalva (que después cambiaría su nombre a F. Madero). El sistema de drenaje maestro de esta vialidad fue construido con ladrillo con argamasa y que se caracteriza por una cubierta en forma de bóveda, sigue la orientación norte-sur de la vialidad formando parte de un sistema de cañerías que comienzan a instalarse para el saneamiento del centro de la ciudad de San Juan Bautista desde por lo menos 1882. Tenemos documentada información histórica que nos señala que para 1922 el caño maestro de la Avenida Grijalva ya estaba instalado. De esta manera el conjunto de rellenos y el sellado de la calle datan de un periodo anterior a este año.
Una vez concluida la construcción del caño, fueron depositados una serie de rellenos bien planificados, con una superposición repetitiva de depósitos de arena sobre estratos de arcilla, que cubrieron la obra hidráulica, y además elevó el nivel del terreno creando una superficie horizontal. Estos rellenos fueron sellados con la instauración de la pavimentación de la calle con un piso de losa de ladrillo. Como parte de estos rellenos fue depositada abundante basura secundaria de artefactos de carácter histórico, entre los que se localizaron ejemplares de teja mecánica. Las tejas fueron registradas en dichos rellenos sobre la avenida Madero, entre su cruce con la avenida Méndez y la calle M. Sánchez (sectores de excavación 1, 3 y 8), de donde se recuperó el $69.3 \%$ de las tejas mecánicas.

El segundo contexto corresponde al sistema de rieles del tranvía que circuló en San Juan Bautista. El sistema de tranvía fue inaugurado en 1896 y deja de estar en función en 1935, cuando quiebra la compañía que ofrecía el servicio. De este sistema, se localizaron segmentos de la superestructura, es decir rieles, sus durmientes, y fijaciones. En la excavación de este contexto se registraron nueve unidades estratigráficas, tanto de origen antró- 
pico como natural. Las tejas recuperadas fueron incorporadas como parte del balasto para el sistema de soporte y estabilidad de los rieles. Las tejas asociadas directamente al sistema de tranvía provienen de dos áreas de excavación que se sitúan en la zona de intersección de la avenida Madero con la calle Zaragoza (Sector de excavación 2 y 4), donde se recuperó el 30.6\% de las tejas (Figura 4).

Es muy probable que las tejas recuperadas en ambos contextos pertenecieran a casas cercanas, ubicadas en la misma avenida o calles anexas, pero para su desecho medio una fase de transporte, por lo cual estos artefactos fueron depositados como basura secundaria. En total se recuperaron tan solo 82 fragmentos de teja de cerámica mecánica, representando el 3.2\% del material arqueológico-histórico documentado (Figura 5).

Este aspecto es importante dado el número limitado de fragmentos de teja francesa obtenidos en la excavación en comparación con otros materiales como la loza cerámica, metales o vidrio (este ultimo por ejemplo, contó con 542 piezas que significó el $21.6 \%$ del total del material). Un problema de investigación que podemos señalar está en relación con el reducido número de estos componentes cerámicos. ¿Por qué razón se localizaron tan pocos ejemplares de teja mecánica?

La búsqueda de una respuesta nos condujo a la utilización de fuentes de analogía mediante dos estrategias. En primer lugar, se utilizó la información histórica como una fuente de hipótesis. Siguiendo esta línea, la pregunta desarrollada está orientada a conocer la cultura material del pasado - entender los porcentajes de material en el contexto arqueológico examinado-, a partir de información histórica que nos refiera conductas del pasado. En este sentido esta primera línea de investigación se ubicaría dentro de la estrategia 1.
La segunda fuente de analogía para entender este problema proviene de la arqueología experimental enfocada a la resistencia de industrias cerámicas (Harry, 2010; Schiffer et al., 1994). En este caso se recurrió a la experimentación con cultura material en el presente para entender la conducta del pasado, lo que correspondería a una estrategia 2 .

El método que seguiremos será deductivo, formulando hipótesis desde ambas fuentes de analogía para posteriormente evaluarlo con el propio registro arqueológico.

\subsection{Una hipótesis desde el registro histórico}

La teja mecánica tiene forma rectangular en planta, en un costado cuenta con una protuberancia y en la cara contraria posee una concavidad; esta característica hace que una teja ensamble con la adyacente. La teja mecánica permitió reducir considerablemente el peso por metro cuadrado de las cubiertas, con $38 \mathrm{~kg}$ por $\mathrm{m}^{2}$ (Orduña, 20022003: 231). También se conoce como teja francesa o marsellesa debido a que su fabricación se llevó a cabo en la mina de arcilla de la Parroquia de Saint Henry, en la ciudad portuaria de Marsella, Francia, entre 1850 y 1950. La fabricación era de tipo industrializado con la introducción de placas en máquinas de vapor, lográndose una producción industrializada de 5000 tejas por jornada para el año de 1850 (Villegas, 2012: 156).

A partir de la segunda mitad del Siglo XIX la teja se convirtió en un producto de uso común para las cubiertas de casas habitación, y otros inmuebles en ciudades tabasqueñas como San Juan Bautista y Frontera. A partir de documentación histórica, Torruco menciona que para 1911 en San Juan Bautista el millar de teja francesa importada se cotizaba a 115 pesos, mientras que la teja criolla se cotiza-

\begin{tabular}{|l|c|c|c|c|c|c|c|c|c|c|c|}
\hline \multirow{2}{*}{ \# Sector } & \multirow{2}{*}{$\begin{array}{c}\text { Total } \\
\text { Fragmentos }\end{array}$} & 1 & 2 & 3 & 4 & 5 & 6 & 7 & 8 & 9 & 10 \\
\hline Sector 1 & 53 & 6 & & & 3 & 3 & 35 & & 6 & & \\
\hline Sector 2 & 8 & & & 1 & 1 & 5 & & & 1 & & \\
\hline Sector 3 & 11 & 9 & & & & & & & 2 & & \\
\hline Sector 4 & 23 & 5 & 4 & 1 & 1 & & & 7 & 3 & 1 & 1 \\
\hline Sector 8 & 6 & 1 & & & & & & & 5 & & \\
\hline
\end{tabular}

Figura 4. Tabla de datos que sintetiza la distribución de tejas mecánicas según el sector de excavación, el número total de tejas y su identificación por tipos. 


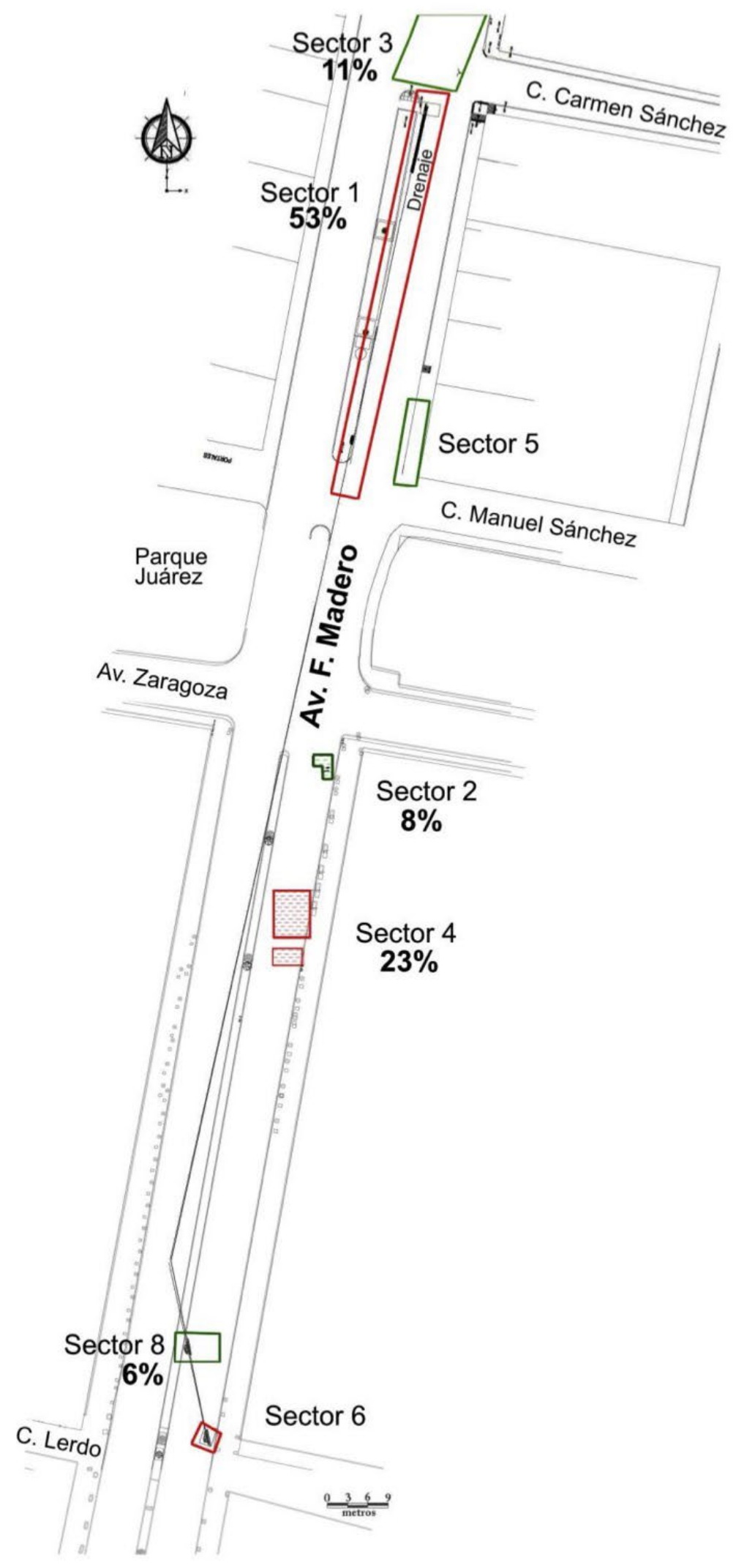

Figura 5. Sectores de excavación en la avenida F. Madero, mostrando el porcentaje de tejas registrado por sector. (Fuente: Elaboración propia). 
ba a 40 pesos, es decir casi una tercera parte del precio del producto francés (Torruco, 1987: 226). Esta situación se entiende debido a que en Tabasco ya se habían desarrollado tejerías árabes o criollas locales, como en el caso de Villahermosa, donde Torruco menciona que para 1899 existía una tejería en Santa Getrudis (Torruco, 1987: 205). Lo anterior significa que en el caso de la teja francesa al tratarse de un bien de importación obtenido por comercio a larga distancia vía marítima, resultaba costosa su adquisición.

La región de Tabasco es una zona aluvial razón por lo cual debía de importar una gran cantidad de productos, entre los que figuraban los elementos de construcción. Para 1899, el ministro residente de Bélgica en México escribe un folleto titulado "La Tierra Caliente Mexicana" en el que señala el comercio de palo de tinte y la importación de productos provenientes de Europa:

"Con la creciente prosperidad del Estado, la importación de materiales para construcción aumenta constantemente, siendo los principales de ellos: la teja francesa, las vigas de hierro, cemento $y$ cal hidráulica en barriles, lozas de mármol -blancas y negras- artículos de gran demanda, etc. Estos materiales proceden principalmente de Hamburgo, Marsella y Barcelona, conducidos por buques noruegos que de vuelta a Europa cargan madera." (Torruco, 1987: 205).

Posteriormente para 1917, en San Juan Bautista se tiene reporte de que la tesorería Municipal carecía de recursos por lo que tenía que recurrir al estado solicitando préstamos. En este contexto resulta pertinente la nota que señala que la tesorería se veía obligada a acciones como vender tejas a particulares (Torruco, 1987: 364). De acuerdo a esto, se deduce que las tejas francesas que cubrían los edificios pertenecientes al Municipio y al Estado, eran desmanteladas para venderlas a particulares y subsanar la carencia de recursos.

Partiendo de las condiciones señaladas por la información histórica, se puede formular el siguiente planteamiento hipotético que guiará la posterior fase de investigación: La teja francesa en San Juan Bautista a pesar de funcionar como un bien utilitario, al ser obtenido por comercio a larga distancia se le consideró un recurso escaso, sumamente valioso y de alto costo de remplazo.

\subsection{Analogía desde la arqueología experimental}

La segunda fuente de hipótesis que empleamos esperando que funcione como referente heurístico, proviene de la arqueología experimental. En este caso la experimentación se enfocó en los patrones de fractura de la teja francesa. El módulo de ruptura o fractura se refiere a la capacidad que tiene un material para resistir al rompimiento bajo una fuerza que se aplica repentinamente (Fournier, 1996: 16).

Para este experimento se utilizó una teja francesa de manufactura contemporánea desechada de las obras de remodelación. Esta pieza estaba conservada en un 70\%. En primer lugar se realizó su registro gráfico y fotográfico, tomando mediciones de varios de sus componentes. Una vez realizado su registro se procedió a fracturarlo. Se dejó caer de una altura de $1.50 \mathrm{~m}$ sobre una superficie de concreto. El artefacto se fracturó al contacto con el suelo, dispersándose en una superficie de $60 \mathrm{~cm}$ por $1.10 \mathrm{~m}$. La mayor parte de las piezas $(14$ fragmentos que significan el 41\%) quedaron concentrados en el área inmediata de impacto. La teja se fragmentó en 34 piezas.

Estos fragmentos se clasificaron de acuerdo a la tipología que establecimos para la teja francesa (Guevara y Pichardo, 2016). Los fragmentos más representados después de que la pieza se fracturó, fueron la sección que va de la parte media del cuerpo a las molduras de la periferia (Tipo 4 de la clasificación y contó con un total de 23 piezas que representa más de la mitad de los fragmentos, 67.6\%). Estos fragmentos carecen de elementos decorativos. Se identificaron numerosos fragmentos menores a $1 \mathrm{~cm}$ de diámetro (un total de 17 que significa la mitad del total de fragmentos, 50\%) y todos ellos pertenecen a la categoría anteriormente descrita. Los siguientes fragmentos representados en mayor proporción son la zona de molduras laterales que muestran decoración de nervaduras y que sirven para encajar con la teja adyacente (Tipo 1), así como ejemplares de la parte media del cuerpo con decoración impresa de letras (Tipo 7); ambos con cuatro fragmentos que significaron el $11.7 \%$ cada uno.

Otro aspecto que nos interesaba era obtener las dimensiones del patrón de fractura de la teja francesa. Se obtuvo que el largo de las piezas varió de $3.2 \mathrm{~cm}$ a $15.5 \mathrm{~cm}$, con un promedio de $9.0 \mathrm{~cm}$ de largo. Mientras el ancho varía de 2.3 a $12.1 \mathrm{~cm}$, con un promedio de $5.0 \mathrm{~cm}$ (Figura 6 ). 
a
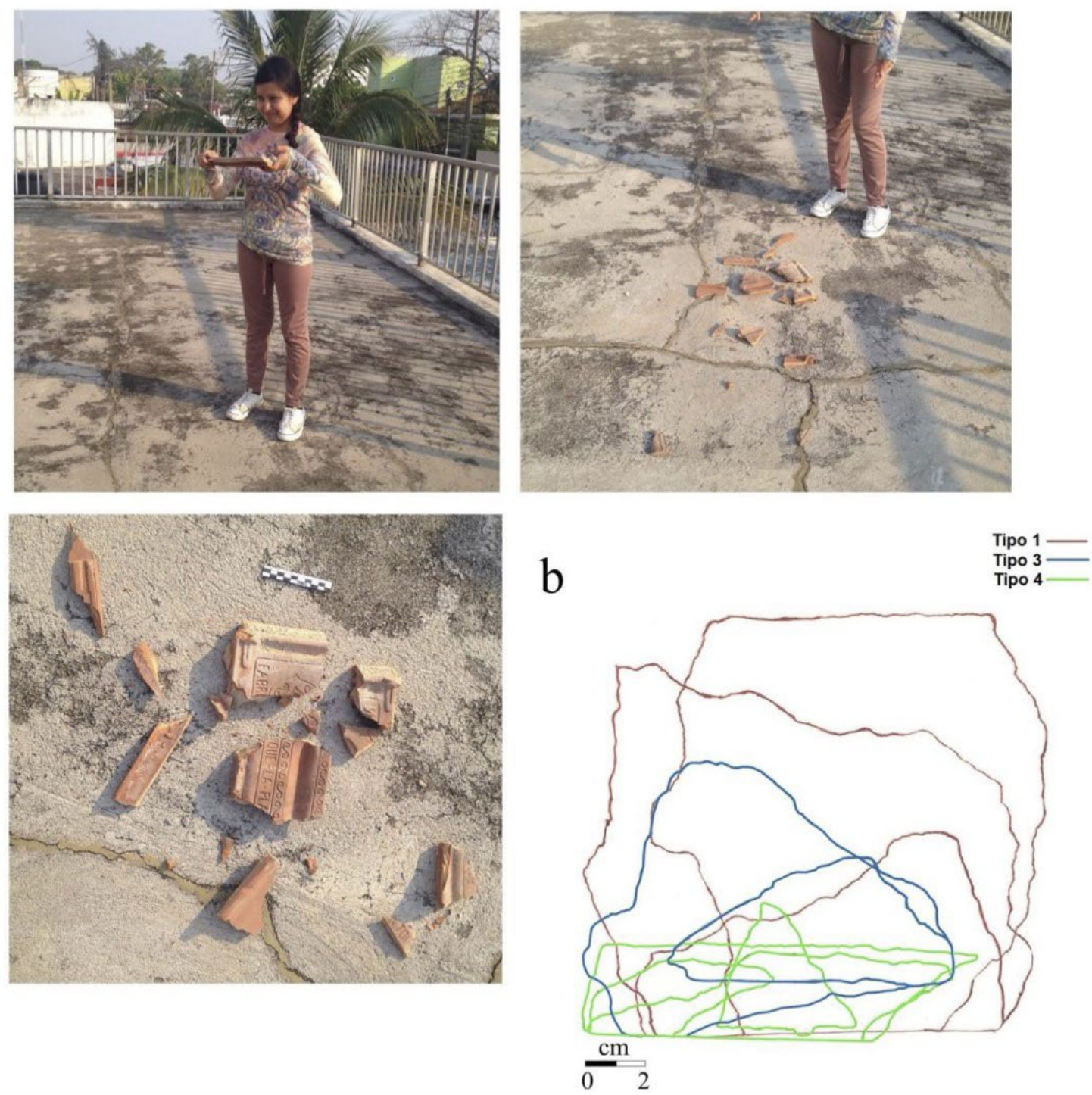

Figura 6. Proceso de fractura de la teja; b. Comparación de las dimensiones de las piezas obtenidas, tipos 1, 3 y 4. (Fuente: Fotografías M. Guevara, México, Noviembre 2015 y diagrama de los autores).

Como resultado del análisis experimental podemos formular el siguiente planteamiento hipotético: La teja francesa muestra un patrón consistente de fracturas en las zonas interiores medias donde la pieza presenta menor resistencia asociado a lo delgado de las paredes en esta sección; en comparación con la zona de los bordes donde se concentran las nervaduras y que tienden a ser de mayor grosor y presentar más resistencia a la fractura.

Ahora bien, para complementar los datos aportados por los patrones de fractura, recurrimos al cálculo del número mínimo de individuos (NMI) que consiste de una estimación indirecta de los individuos representados en el conjunto de restos de una muestra (NR, que en nuestro caso arroja un total de 82 fragmentos de teja). Existen varias metodologías para calcular el NMI; en este caso utilizaremos el más empleado, que consiste en el siguiente proceso: identificar los elementos diagnósticos que permita asignarlos a un individuo o unidad, y la estimación del número de ejemplares de la misma, obteniéndose así la frecuencia relativa.

En las tejas dicho elemento diagnóstico son los fragmentos con marcas y sellos, que en nuestra clasificación corresponden al Tipo 2, con sello, al 
Tipo 3, con impresión y al Tipo 7, con nervaduras e impresión (Guevara y Pichardo, 2016). La tipografía y los sellos son fácilmente reconocibles e individualizantes para cada unidad. Así, su identificación y contabilización puede permitir la estimación del número máximo de individuos. Del tipo 2 se identificaron 4 fragmentos con sello, cada una refiriendo a una pieza individual. Del tipo 3 se registraron 2 fragmentos, asignables a dos distintas piezas. Para el tipo 7 se contabilizaron 12 fragmentos. Al hacer la revisión del contexto de proveniencia y las distintas impresiones tipográficas, se deduce que provienen de dos piezas. A esto debemos sumar las dos piezas restaurables recuperadas, con lo cual se obtiene que el NMI es de 10 piezas.

Hay que tomar en consideración que existen una serie de variables que afectan las relaciones entre NR y NMI (Castaños, 1984: 320). La primera de estas envuelve los procedimientos de registro en campo y de análisis en laboratorio. Se basa en que todos los restos de la muestra, que corresponde al NR, tienen la misma posibilidad de ser registrados y colectados en el trabajo de excavación, e identificados tipológicamente en su totalidad durante el análisis.

El estado de fragmentación de los propios restos puede modificar notablemente la capacidad de discriminación específica del tipo que se trata. Este no fue el caso para la clasificación de teja mecánica, donde los atributos, aún en las piezas de dimensiones menores, resultan suficientes para definir con precisión la asignación a cada tipo. En cuanto a la metodología de registro y recuperación en excavación, procuró ser detallada. A pesar de esto, si evaluamos los patrones de fractura se debe contemplar la proporción de materiales pequeños menores a $1 \mathrm{~cm}$ de diámetro (que representa el $50 \%$ de una teja al fragmentarse). De igual forma hay que considerar la estimación de los segmentos de tejas menos conservados, donde encontramos que precisamente el tipo 3 , uno de nuestros elementos diagnósticos para el cálculo del NMI, es el menos representado. Consiste de fragmentos del cuerpo medio de la pieza, que es la sección de menor resistencia a la fractura. Finalmente con los datos de cálculo del NMI, evaluamos que se recuperó el $41 \%$ del total de los materiales del universo total previsible.

Lo anterior puede ser consecuencia de la parcial recuperación de los fragmentos durante el procesos de excavación y registro, en especial aquellos menores a $1 \mathrm{~cm}$ de diámetro. Pero también puede involucrar conductas de formación del contexto, donde cabe la posibilidad que no todas las piezas de teja fueran desechadas precisamente en estos rellenos y basureros. Otro motivo tiene que ver con la segunda variable relacionada con la teoría observacional y que se refiere a los procesos post-deposicionales de degradación. En especial porque se trata de una zona de suelo ácidos y de humedales, donde las piezas cerámicas estuvieron expuestos a severa humedad y que incide en las propiedades físico-químicas de los materiales. Tales condiciones que involucra la recuperación, las conductas de formación y los procesos post-deposicionales, pueden estar en relación directa con la conservación diferencial de cada parte de la teja y que inciden finalmente en el cálculo del NMI.

\subsection{Implicaciones contrastadoras de las hipó- tesis}

En este punto debemos retomar los planteamientos hipotéticos formulados desde las dos fuentes de analogía y evaluarlos a través del registro arqueológico. Para lograrlo debemos primero derivar los efectos observables en el caso de que las conjeturas planteadas sean correctas. A esto se le conoce como implicaciones contrastadoras de la hipótesis (Hempel, 1973: 21). Se formulan en términos condicionales y nos dicen bajo qué condiciones de contrastación especificadas se producirá un resultado de determinado tipo (Hempel, 1973: 38). Se efectuó mediante el procedimiento lógico modus tollens que básicamente consiste en plantear una premisa considerada verdadera, la cual corresponde a la hipótesis, y a continuación deducir un conjunto de conclusiones que corresponden a las implicaciones contrastadoras.

\section{- Hipótesis 1}

La teja francesa en San Juan Bautista a pesar de haber funcionado como un bien utilitario, al ser obtenido por comercio a larga distancia se le consideró un recurso escaso, sumamente valioso y de alto costo de remplazo.

\section{- Implicaciones contrastadoras}

Si la teja francesa, al ser un bien obtenido mediante comercio a larga distancia, resulta un recurso escaso, de amplio valor y alto costo de remplazo, entonces se esperaría que:

- Se trate de artefactos con una vida útil muy larga. 
Por esta razón cabría esperar que:

- Ocurrieran amplias conductas de ciclaje lateral.

- Ocurrieran amplias conductas de ciclaje lateral.

- Tuvieran lugar conductas de recuperación y rescate de piezas (scavenging en el término original de Schiffer, 1988).

\section{- Indicadores arqueológicos}

- Habrá un decremento en la proporción de desecho de la teja francesa en términos de densidad, variedad y frecuencia.

- Piezas semi-completas o restaurables estarían prácticamente ausentes en el registro arqueológico.

\section{- Hipótesis 2}

La fractura de la teja francesa muestra un patrón consistente de fracturas en las zonas interiores medias donde la pieza, que presentan una menor resistencia asociado a lo delgado de las paredes en esta sección; en comparación con la zona de los bordes donde se concentran las nervaduras y que tienden a ser de mayor grosor y presentar más resistencia a la fractura.

\section{- Implicaciones contrastadoras}

Si la teja francesa presenta una menor resistencia en las zonas interiores de la parte media del cuerpo donde la pieza es más delgada en sus paredes en esta sección, entonces:

- Esta sección media mostrará un patrón más consistente de fracturas y una frecuencia más alta.

Por otro lado en la zona de los bordes se concentran las nervaduras y que tienden a ser de mayor grosor, entonces

- La zona de bordes con nervadura deberá presentar más resistencia a la fractura .

Indicadores arqueológicos

- Habrá una mayor frecuencia de fragmentos de teja del tipo 4, seguidas por tejas del tipo 1 y 7 . - Cerca de la mitad de los materiales recuperados deberán tener $45 \mathrm{~cm}^{3}$ de volumen (con dimensiones promedio de 9 por $5 \mathrm{~cm}$ ).

\section{Conclusiones. La ciencia de la deducción}

Para evaluar las hipótesis derivadas por analogías de documentación histórica y experimentación arqueológica, se recurrió al análisis de las marcas o huellas (trace) que presentan formalmente los artefactos, y que se refiere a la modifi- cación física de un artefacto. Sullivan (citado por Schiffer, 1987: 15) la define como una alteración en las propiedades físicas de un objeto o una superficie. Así que se trata de cualquier consecuencia perceptible de una actividad o proceso.

Como se desprende de la información histórica, la teja mecánica en San Juan Bautista fue un bien utilitario obtenido por comercio a larga distancia. Lo anterior se puede contrastar por medio de las características formales de los artefactos. Arqueológicamente contamos con información que nos refiere al lugar de producción de las tejas. En la decoración se observan marcas de sellos mediante los cuales se puede identificar la fábrica donde fue realizada, ya que cada fabricante tenía un sello particular para sus tejas. De igual manera se puede identificar una decoración mediante impresión en bajo relieve en el cuerpo de la teja, que corresponde a nombres propios de la fábrica productora, así como del lugar de fabricación. Por las marcas decorativas de sello e impresión, sabemos que las tejas recuperadas en contexto arqueológico provenían de las fábricas Pierre Sacoman, Saumati Frère y Guichard Carvin et Compagnie, en Marsella, Francia.

Otro de los puntos a evaluar era conocer la etapa del ciclo de vida en que se encontraban estos elementos duraderos. Nos interesaba saber si se trataba de bienes sin usar, o por el contrario advertir si fueron bienes que tuvieron una etapa de uso-consumo y posteriormente fueron desechados. El análisis de marcas nos permite señalar que se trataron de tejas que tuvieron una etapa de uso. Lo anterior se percibió por los patrones de daños que poseen. Se apreciaron ligeras marcas de erosión en la cara funcional exterior, en especial en las acanaladuras debido seguramente a la acción de procesos naturales como el agua. De igual forma hay crecimiento de líquenes, común en su exposición al agua y al sol en su etapa de uso. Por otro lado, un gran número de piezas poseen restos de mezcla de argamasa. Lo anterior nos permite señalar que fueron piezas empleadas como cubiertas en su etapa de uso.

En los ejemplares obtenidos no hay evidencia de mantenimiento que haga pensar en ciclaje lateral, pero pudo haber ocurrido este proceso. Finalmente, las tejas fueron desechadas en basureros improvisados durante la etapa de construcción de relleno para desplantar la calle. Es muy probable que las tejas pertenecieran a inmuebles cercanos, ubicadas en la misma vialidad o cercana a ella, pero para su desecho medió una fase de transpor- 
te, por lo cual estos artefactos fueron depositados como basura secundaria (Figura 7).

En cuanto a las dimensiones de fractura coinciden en el caso experimental y el arqueológico en sus propiedades promedio de largo y ancho. En el experimento, la longitud promedio es de $9.0 \mathrm{~cm}$ de largo con un promedio de $5.0 \mathrm{~cm}$ de ancho. En el registro arqueológico lo fragmentos de teja poseían un promedio de $8.0 \mathrm{~cm}$ de longitud por $6.0 \mathrm{~cm}$ de ancho. Nuestro planteamiento hipotético señalaba que las piezas semi-completas o restaurables estarían prácticamente ausentes en el registro arqueológico. No obstante se localizaron dos tejas francesas que poseían la mayor parte de sus atributos (nervaduras, sellos, impresión), considerándose como piezas semi-completas o restaurables, en las que se conservaba entre el 40 y $70 \%$ de la pieza (Figura 8).

A partir del sistema tipológico que se realizó de los materiales arqueológicos, pudimos determinar no solo la cantidad, sino la contabilización de la sección de la teja recuperada. El tipo de teja más representado en la muestra es el tipo 1 (21\%), seguido por el tipo $8(17 \%)$ y tipo $7(12 \%)$. Como vemos hay ausencia del tipo 4 en las tejas arqueológicas, pero hay una coincidencia en los altos porcentajes de los tipos 1 y 7 tanto en el ejercicio experimental como en el contexto arqueológico. En esta situación habría que formular una hipótesis auxiliar que explicara la ausencia de altos porcen- tajes de fragmentos de teja del tipo 4 en los basureros arqueológicos.

Siguiendo con la evaluación de la hipótesis, se esperaría encontrar baja frecuencia de estos materiales depositados como desechos secundarios. Se recuperaron tan solo 82 fragmentos de teja francesa dentro del total del área de excavación que alcanzó $709 \mathrm{~m}^{2}$. Si tomamos en consideración los patrones de ruptura de los materiales del caso experimental, podemos calcular que una pieza completa en promedio se fractura en 48.5 fragmentos. Lo anterior, aunado al cálculo del NMI, significa que no se contaría con más de ocho tejas desechadas en estos extensos basureros, además de dos tejas restaurables. ¿Por qué razón hay un patrón de desecho de teja marsellesa tan bajo?

La repuesta pudiera encontrarse en que estos artefactos se caracterizan por presentar una esperanza de vida útil prolongada. A medida de que hay un decremento en la proporción de frecuencia de desecho final de un elemento duradero, como en este caso la teja francesa, cabe la posibilidad de que haya un incremento en la probabilidad de que estos elementos tuvieran una vida útil larga. La vida útil de estos artefactos (Schiffer, 1988: 15) puede considerarse en una escala ordinal general como alta (Figura 9).

Otro factor pudo ser el costo de remplazo. Debido a que se trataban de bienes obtenidos por comercio a larga distancia, debió resultar difícil su

\section{a}

contexto sistémico

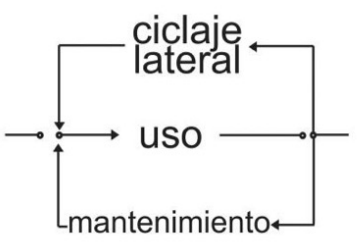

b

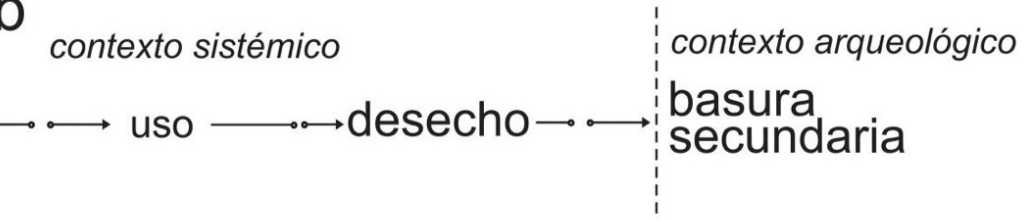

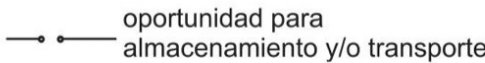

Figura 7. Ciclo de vida de la teja mecánica de San Juan Bautista: a. Tejas completas o restaurables que son retenidas en contexto sistémico por conductas de rescate y ciclaje lateral, con etapas de mantenimiento; b. Fragmentos de tejas recuperados en el contexto arqueológico desechadas como basura secundaria. (Fuente: Modificado de Schiffer, 1972). 

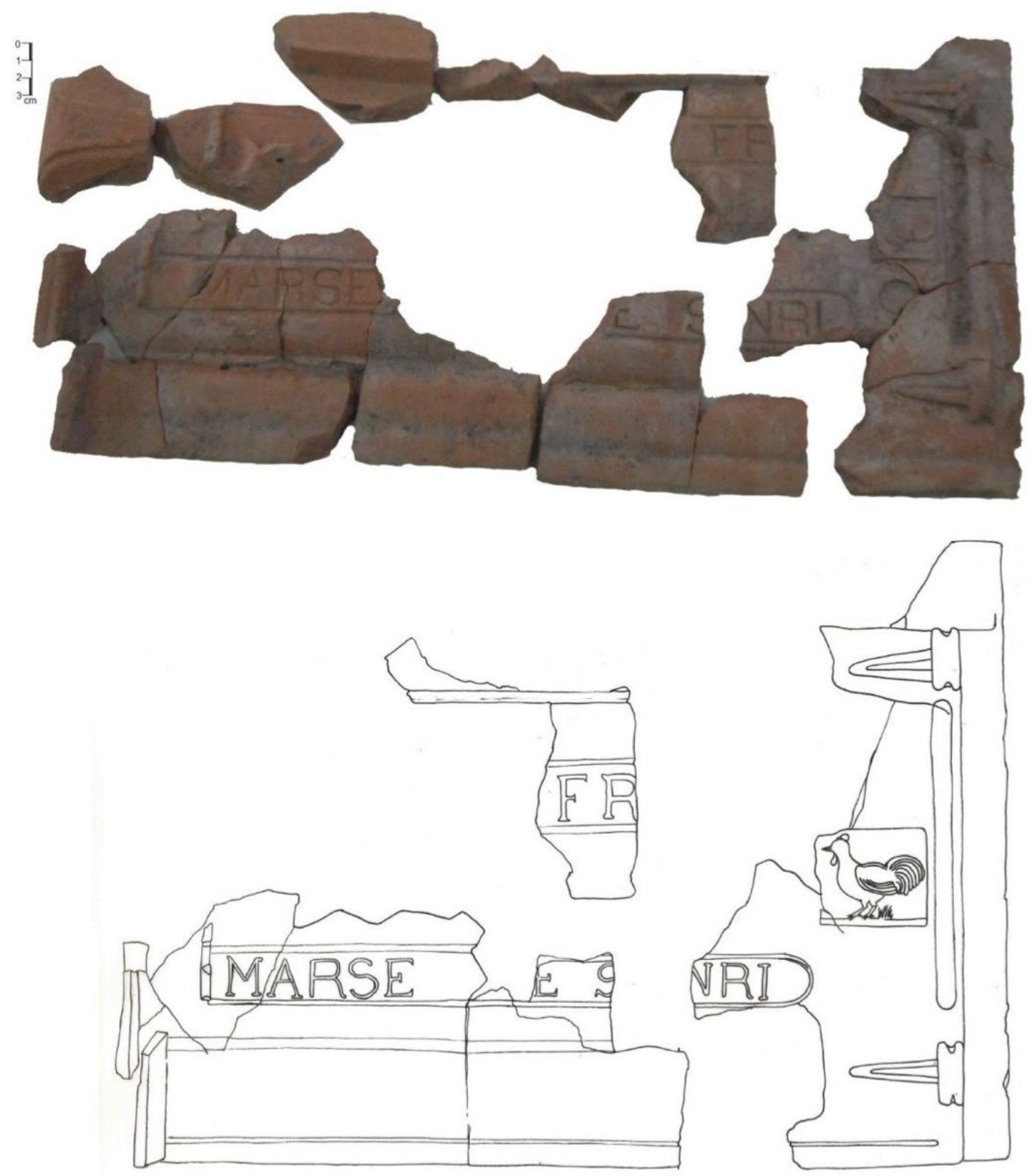

Figura 8. Ejemplo de teja francesa semi-completa recuperada en excavación. (Fuente: Fotografía y dibujo de los autores).

re-abastecimiento, debido a la distancia de la fuente de producción y la complejidad de los procesos de comercio, especialmente el trasporte. A causa de estos factores el costo de remplazó debió ser muy alto en las décadas finales del siglo XIX.

Si sumamos el conjunto de características de las tejas francesas, al tratarse de artefactos moderadamente portátiles, con altos costos de remplazo y una vida remanente útil alta, es muy posible que conductas como la curaduría hayan actuado disminuyendo la cantidad de artefactos que fueron finalmente depositados como basura secun- daria en un número reducido.

El uso de información proveniente del registro histórico es una parte constitutiva de la teoría arqueológica. Su empleo en nuestra disciplina es posible a través de la analogía, al funcionar en términos heurísticos, esto es, nos permite derivar hipótesis de investigación. Lo anterior nos ofrecería la posibilidad de evaluar a través de un método deductivo, los datos provenientes de otras disciplinas, en este caso la historia, a partir del registro arqueológico. Así nuestra propia teoría se enriquece.

De otra forma, procederíamos en términos in- 


\begin{tabular}{|l|l|l|l|l|}
\hline Propiedades & Portabilidad & $\begin{array}{l}\text { Costo de } \\
\text { remplazo }\end{array}$ & $\begin{array}{l}\text { Vida útil } \\
\text { remanente }\end{array}$ & Dimensiones \\
\hline Fragmentado & $\begin{array}{l}\text { Moderadamente } \\
\text { portátil }\end{array}$ & Alto & Alto & $\begin{array}{l}50 \times 26 \mathrm{~cm} \\
\text { (completo) }\end{array}$ \\
\hline $\begin{array}{l}\text { Desgaste ligero } \\
\text { o moderado }\end{array}$ & & & $\begin{array}{l}6 \times 8 \mathrm{~cm} \text { (patrón } \\
\text { de fractura) }\end{array}$ \\
\hline
\end{tabular}

Figura 9. Tabla de propiedades de la teja francesa. (Fuente: Basado en Schiffer, 1988: 23).

ductivos. ¿Cuál es la desventaja de este otro método? Las generalizaciones inductivas, poseen serios problemas epistémicos (Hempel, 1973). El reduccionismo teórico que significa la dependencia de nuestra disciplina a otros campos de conocimiento, como la historia por ejemplo. 0 la generación de discursos tautológicos donde se parte del dato histórico como explicación directa sin que exista una aportación desde el registro arqueológico y por lo tanto sin un avance en el conocimiento. Estos son solo algunos de los serios problemas que pretendemos evitar. Y es la ventaja de una ciencia de la deducción.

\section{Bibliografía}

ANDRÉN, Anders. 1998: Between artefacts and texts: Historical archaeology in global perspective. Plenum Press. New York.

BATE, Luis F. 1998: El Proceso de Investigación en Arqueología. Crítica. Barcelona.

BATE, L. Felipe; TERRAZAS, Alejandro. 2006: "Apuntes sobre las investigaciones prehistóricas en México y América". Boletín antropológico, 24 (67), pp. 167-219.

BINFORD, Lewis R. 1988: En busca del pasado. Crítica. Barcelona.

BLOUET, Helen. 2014: "Caribbean Historical Archaeology". En C. SMITH (ed.): Encyclopedia of global archaeology, pp. 1156-1160. Springer. Nueva York.

CASTAÑOS UGARTE, Pedro. 1984: "Algunas observaciones acerca del numero de restos (NR) y del numero mínimo de, individuos (NMI) en los estudios de arqueozoologia". KOBIE Revista de Ciencias, XIV, pp. 319-322.

DECORSE, Christopher. 2014: "Historical archeology: methods, meanings and ambiguities". En M. E. DAKUBU; A. AIKINS; K. KORAM y C. MATE-KOLE (eds.): Current Perspectives in the
Archaeology of Ghana. Department of Archaeology and Heritage Studies, Social Science Series (6), pp. 139-163. Universsidad de Ghana. Legon.

DEETZ, James. 1977: In Small Things Forgotten: the archaeology of early American life. Garden City-Anchor Books. New York.

FOURNIER GARCÍA, Patricia. 1985: "Arqueología histórica en la Ciudad de México". Boletín de Antropología Americana, 11, pp. 27-31.

FOURNIER GARCÍA, Patricia. 1996: La alfarería tradicional: Resistencia a la ruptura en cuerpos cerámicos. INAH. México.

FOURNIER GARCÍA, Patricia; CHARLTON, Thomas. 2012: "Historical archaeology in central and western Mesoamerica". En D. NICHOLS y C. POOL (eds.): The Oxford Handbook of mesoamerican archaeology, pp. 916-932. Oxford University Press. Oxford.

FUNARI, Pedro. 2008: "La arqueología histórica mundial y latinoamericana en las últimas dos décadas". Revista de Arqueología Histórica Argentina y Latinoamericana, 2, pp. 11-15.

FUNARI, Pedro.; HALL, Martin; JONES, Sian (eds). 1999: Historical archaeology: Back from the edge. Routledge. London.

GÁNDARA VÁZQUEZ, Manuel. 1990: "La analogía etnográfica como heurística: lógica muestreal, dominios ontológicos e historicidad". En M. SERRA y Y. SUGIURA (eds.): Etnoarqueología. Coloquio Boch-Gimpera, pp. 43-82. UNAM. México.

GÁNDARA VÁZQUEZ, Manuel. 2007: El análisis teórico en ciencias sociales: Aplicación a una teoría del origen del estado en Mesoamérica. Tesis doctoral. ENAH. México.

GUEVARA CHUMACERO, Miguel. 1997: "La analogía como una forma de argumentación en arqueología”. Actualidades Arqueológicas, 11, pp. 7-8. 
GUEVARA CHUMACERO, Miguel; PICHARDO FRAGOSO, Alejandra. 2016: "El comercio en San Juan Bautista, Tabasco, en la transición de los siglos XIX al XX. Perspectivas desde la arqueología histórica". En Memorias del encuentro internacional de los investigadores de la cultura maya, 25 (II), pp. 249-263. UAC. México.

HALL, Martin; SILLIMAN, Stephen. 2006: "Introduction: Archaeology of the Modern World". En M. HALL y S. SILLIMAN (eds.): Historical archaeology, pp. 1-19. Blackwell Malden. Oxford.

HARRY, Karen G. 2010: "Understanding ceramic manufacturing technology: the role of experimental archaeology". En J. FERGUSON (ed.): Designing experimental research in archaeology. University Press of Colorado. Boulder.

HEMPEL, Carl. 1973: Filosofía de la ciencia natural. Alianza Editorial. Madrid.

LEES, William; KING, Julia. 2007: "What Are We Really Learning through Publicly Funded Historical Archaeology (and Is It Worth the Considerable Expense?)". Historical archeology, 41, pp. 54-61.

LÓPEZ AGUILAR, Fernando. 1990: Elementos para una construcción teórica en arqueología. INAH. México.

MEHLER, Natascha. 2013: "Globalization, immigration, and transformation: Thoughts from a european perspective". Historical Archaeology, 47 (1), pp. 38-49.

MONTÓN SUBÍAS, Sandra; ABEJEZ, Luis. 2015: “¿Qué es esa cosa llamada arqueología histórica?". Complutum, 26 (1), pp. 11-35.

ORDUNA PORTÚS, Pablo M. 2002-2003: “La gran tejería mecánica de Mendillorri: trabajo práctico de Arqueología industrial". Trabajos de Arqueología Navarra, 16, pp. 227-242.

ORSER, Charles. E. 1996: A historical archaeology of the modern world. Plenum Press. New York.

ORSER, Charles. E. 2012: "An archaeology of eurocentrism". American Anthropologist, 77 (4), pp. 737-755.

POPPER, Karl. 1983: Conjeturas y refutaciones. El desarrollo del conocimiento científico. Paidós. Barcelona.

REID, Jefferson. 1995: "Four strategies after twenty years: A return to basics". En J. SKIBO; W. WALKER y A. NIELSEN (eds.): Expanding archaeology, pp. 15-21. University of Utah Press. Salt Lake City.
REID, Jefferson; SCHIFFER, Michael; RATHJE, William. 1975: "Behavioral archaeology: Four strategies". American Anthropologist, 77, pp. 864-869.

SAUCEDO SEGAMI, Daniel; CHIRINOS OGATA, Patricia. 2020: "Historical Archaeology in Peru". En C. SMITH (ed.): Encyclopedy of Global Archaeology, pp. 2-10. Springer. Suiza.

SCHIFFER, Michael. 1972: "Archaeological context and systemic context". American Antiquity, 37 (2), pp. 156-165.

SCHIFFER, Michael. 1987: Formation processes of the archaeological record. University of New Mexico Press. Albuquerque.

SCHIFFER, Michael. 1988: "Existe una premisa pompeya en arqueología”. Boletín de Antropología Americana, 18, pp. 5-31.

SCHIFFER, Michael B.; SKIBO, James M.; BOELKE, Tamara C.; NEUPERT, Mark A.; ARONSON, Meredith. 1994: "New perspectives on experimental archaeology: Surface treatments and thermal response of the clay cooking Pot". American Antiquity, 59 (2), pp. 197-217.

SCHUYLER, Robert. 1978: "Historical and historic sites archaeology: Definitions and relationships". En R.L. SCHUYLER (ed.): Historical archaeology: A guide to sustantive and theoretical contributions, pp. 27-32. Baywood Publishing Company. New York.

SOUTH, Stanley. 1977: Method and Theory in Historical Archeology. Academic Press. New York.

STILES, Daniel. 1977: "Ethnoarcheology: a discussion of methods and applications". Man, 12 (1), pp. 87-103.

TORRUCO SARAVIA, Geney. 1987: Villahermosa nuestra ciudad. Tomo I. Ayuntamiento del Centro. Tabasco.

VILLEGAS, Pascale. 2012: "Las tejas de Marsella en la costa campechana. Estudio preliminar". En S. LADRÓN; L. BUDAR, y R. LUNAGÓMEZ (eds.): Haciendo Arqueología. Teoría, métodos y técnicas, pp. 154-164. Universidad Veracruzana. México. 